\section{Protección antituberculosa para el personal de salud ${ }^{1}$}

1 Extractado de: Harries AD, Maher D, Nunn P. Practical and affordable measures for the protection of health care workers from tuberculosis in low-income countries. Bull World Health Organ 1997;75: 477-489.
Antes de que se generalizara el uso de tratamientos eficaces, la tuberculosis (TB) representaba un riesgo siempre presente para el personal de salud, en particular para los que trabajaban en sanatorios. Alrededor de 1950 empezó a extenderse el uso de la quimioterapia antituberculosa y el riesgo empezó a disminuir notablemente junto con la incidencia de la enfermedad. Dentro de los países industrializados la TB se convirtió en pocos años en una enfermedad casi desconocida. Sin embargo, en los años ochenta la enfermedad tuvo un resurgimiento vigoroso y se ha constituido de nuevo no solo en un peligro para la población en general sino también en un problema ocupacional para los trabajadores de salud. En 1993 en los Estados Unidos, 3,2\% de los casos de TB correspondieron a personal de salud. Si bien en ese país la incidencia de TB aumentó 20\% de 1985 a 1992, algo muy parecido ocurrió en otros países. Por ejemplo, en Dinamarca tuvo un aumento de $20 \%$ entre 1986 y 1992; en Italia aumentó 27\% de 1988 a 1992; y en España, 28\% de 1990 a 1992.

A medida que el personal de salud familiarizado con la enfermedad se ha ido jubilando, ha quedado toda una generación de médicos para quienes la TB es una enfermedad fuera de lo común con un lugar insignificante en la lista de diagnósticos diferenciales. Además, las prácticas destinadas a su prevención se fueron abandonando poco a poco por considerarse innecesarias. La aparición de cepas resistentes a varios medicamentos contribuyó enormemente a la dispersión de la TB dentro de los hospitales porque los medicamentos de primera línea se volvieron ineficaces. Actualmente están en máximo riesgo de infección nosocomial de TB los pacientes y el personal inmunocomprometidos, sobre todo los que tienen infección por el virus de la inmunodeficiencia humana (VIH). Entre el personal de salud que corre mayor riesgo de TB se destaca en primer lugar el de enfermería por su contacto cercano y prolongado con los pacientes. Los médicos de 20 a 35 años de edad y los internistas, especialistas en medicina del aparato respiratorio y patólogos experimentan también altas tasas de infección y enfermedad. El personal de laboratorio se puede infectar con TB por inhalación o inoculación accidental y se estima que corre un riesgo de contraer TB de dos a nueve veces mayor que el del público general. Por supuesto, el riesgo es mucho más alto para los que tienen la infección por VIH y en una 
revisión reciente se informó que ocho de 17 trabajadores de salud con TB polifarmacorresistente dieron resultados positivos a las pruebas de detección de ese virus.

Es importante tener en cuenta que la transmisión nosocomial aumenta cuando no se diagnostica rápidamente a los pacientes, cuando estos no reciben el tratamiento adecuado o cuando son portadores de cepas resistentes no reconocidas. Los pacientes más infecciosos son los de enfermedad pulmonar positivos a los frotis de esputo y por tal motivo los casos sospechosos de TB pulmonar deben ser examinados con toda rapidez. Sin embargo, en países como los Estados Unidos, donde por largo tiempo no se solía encontrar TB, a veces no se realizan las pruebas de esputo ni se procede rutinariamente a determinar la sensibilidad de los aislados. En vista de la situación descrita, en 1990 los Centros para el Control y la Prevención de Enfermedades (EUA) emitieron una serie de directrices preventivas, que se resumen a continuación, con objeto de evitar la diseminación de TB en las instituciones de salud.

\section{Medidas preventivas}

Las intervenciones que se enumeran a continuación han contribuido a la reducción de la transmisión nosocomial de la TB polifarmacorresistente en un pabellón de pacientes con infección por VIH en los Estados Unidos de América:

\section{Medidas administrativas}

Instalar una oficina de control de la TB dotada de un director, un asesor de salud pública y trabajadores extrainstitucionales

\section{Medidas diagnósticas}

Fomentar la formación de conciencia sobre la TB entre los pacientes positivos al VIH que tengan enfermedades respiratorias

Establecer una política de siempre "descartar la posibilidad de $\mathrm{TB}^{\prime \prime}$

- Los pacientes con sospecha de TB, neumonía por Pneumocystis carinii o radiografía anormal del pecho deben ser mantenidos en un salón de aislamiento para casos de TB.

- Los procedimientos para recoger esputos y administrar tratamientos de pentamidina en aerosol solo deben tener lugar en el salón de aislamiento.

- Debe aumentarse el número de técnicos en los laboratorios para micobacterias y contarse con la capacidad para realizar como rutina diaria frotis urgentes para la detección de bacilos acidorresistentes.
Medidas terapéuticas

El tratamiento antituberculoso inicial debe ampliarse para incluir cuatro medicamentos.

Los pacientes no deben salir de los salones de aislamiento para casos de TB a menos que lo requiera algún procedimiento y que lleven puestas mascarillas sanitarias.

Los salones de aislamiento deben tener puertas que se cierran automáticamente.

Debe instalarse presión atmosférica negativa en los salones de aislamiento.

El aislamiento de pacientes debe continuarse hasta obtener por lo menos tres frotis de esputo exentos de bacilos acidorresistentes.

Medidas para proteger al personal de salud

Prohibir que los trabajadores inmunocomprometidos trabajen en los pabellones médicos.

Insistir en que todo el personal que entre en un salón de aislamiento para casos de TB lleve puestas mascarillas submicrónicas y encima una careta respiratoria a prueba de partículas de polvo y aerosoles.

Administrar a los trabajadores de salud la prueba de la tuberculina cada 4 meses.

\section{Factores de transmisión}

Se llama la atención a una serie de factores que se asocian con la transmisión de la TB al personal de salud en los países industrializados y que pueden interesar en otros lugares del mundo:

- Demoras en el diagnóstico de la TB

- Procedimientos asociados con la aerosolización de los bacilos tuberculosos:

Intubación

Broncoscopia

Inducción de esputo

Ventilación mecánica

Irrigación a presión de abscesos tuberculosos

Cambio de vendajes de úlceras tuberculosas

Autopsia

- TB polifarmacorresistente

- Protección personal descuidada

Uso insuficiente de mascarillas

- Procesos de ventilación deficientes

Puertas abiertas al salón de aislamiento de la TB

Ventilación insuficiente en los salones de aislamiento de la TB o los pabellones

Presión atmosférica positiva en los salones de aislamiento de la TB

Presión atmosférica positiva en los salones donde se dispensa pentamidina en aerosol

Ventilación recirculatoria 
Puesto que el método más ahorrativo de interrumpir la cadena de transmisión de la TB es el rápido diagnóstico y tratamiento de pacientes infecciosos, para ese fin se recomiendan los principios y procedimientos que se explican seguidamente.

\section{Manejo de casos sospechosos de TB}

En las áreas con prevalencias altas de TB debe investigarse a cualquier paciente que tenga tos por más de 3 semanas. Esto es especialmente importante si el paciente ha perdido peso y si no ha respondido a un régimen de antibióticos. También deben investigarse todos los pacientes con expectoración de sangre, independientemente de la duración de este síntoma.

Muchos pacientes con frotis positivos a la TB permanecen ambulatorios hasta el momento de comenzar su tratamiento. Para el personal de salud y quizá también para los pacientes puede ser conveniente hospitalizarlos hasta investigar la posibilidad de TB pulmonar. No obstante, siempre que sea posible los pacientes ambulatorios deben ser examinados como pacientes externos. Para saber el paradero de pacientes con frotis positivos, lo más apropiado es que todos sean tamizados por una oficina (como la oficina distrital de TB). Además, es importante mantener un registro de pacientes ambulatorios con tos y otro registro de examen de esputos en el laboratorio. En el registro de la tos se guardan el nombre y la dirección de los pacientes con sospecha de tener TB, la fecha de entrega de las muestras de esputo, fecha en que el personal de salud recibe los resultados, resultados de los frotis y fecha en que el paciente vuelve a recoger los resultados. De esta forma se puede localizar a los pacientes con frotis positivos que no hayan vuelto por sus resultados.

En algunos lugares se ha acostumbrado tomar muestras de esputo durante tres mañanas consecutivas de los pacientes recién hospitalizados. Para agilizar la recolección de muestras y la entrega de los resultados, ahora se recomienda que los tres especímenes se recojan en 24 horas: uno bajo supervisión en el momento en que se admite al paciente, uno temprano la siguiente mañana y otro bajo supervisión 2 horas más tarde.

- Aun con el método de 24 horas suelen ocurrir demoras. El personal a veces se olvida de solicitar los especímenes de esputo por varios días después de admitido el paciente. Otras veces no se le proporciona a este un envase para recoger el esputo, o puede ser que el paciente no entienda cómo producirlo y entregarlo. También es posible que sean muy lentas la ida de las muestras de esputo al laboratorio y la vuelta de los resultados. Una solución potencial es designar a una persona como oficial de servicio en el pabellón para que se encargue exclusivamente de todos los aspectos relacionados con la recolección de muestras de esputo y de los resultados. Este oficial puede hacerse responsable de que todos los pacientes con especímenes positivos al bacilo de la TB estén registrados y de que su tratamiento empiece en cuanto se sepa el diagnóstico. Las responsabilidades de este oficial son las siguientes:

- Con ayuda del personal clínico y de enfermería, identificar mañana y tarde en su pabellón a las personas a quienes se sospecha de tener TB.

- Proporcionar envases a los pacientes tan pronto llegan y educarlos en la forma de producir y entregar las muestras de esputo.

- Llevar las muestras y los formularios correspondientes debidamente llenados todas las mañanas al laboratorio.

- Recoger los resultados de laboratorio todas las mañanas y guardarlos en los archivos de los pacientes.

- En el caso de un paciente con resultados positivos a la TB, tan pronto como se reciba el diagnóstico llevar al paciente con su carpeta y formulario de resultados a registrarse en la oficina distrital sobre TB para comenzar su tratamiento.

- Ofrecer diariamente sesiones de instrucción sobre la enfermedad a todos los pacientes con sospecha de TB en el pabellón.

- Registrar en un "registro de pacientes con tos" el nombre de cada paciente, su edad, sexo, dirección, fecha en que se le proporcionaron envases para esputo, fecha en que las muestras se llevaron al laboratorio, fecha y resultados del examen de las muestras y fecha en que los pacientes con resultados positivos comenzaron el tratamiento antituberculoso.

\section{Para mayor seguridad en el laboratorio}

En los países de bajos ingresos pueden seguirse los siguientes lineamientos para conseguir la máxima seguridad del personal al examinar muestras de esputo que contienen micobacterias.

- Debe tratarse de evitar, reducir o controlar los procedimientos de laboratorio que crean aerosoles potencialmente infecciosos.

- Para mayor protección del personal de laboratorio, debe disponerse de un gabinete de seguridad para preparar y fijar los frotis y procesar especímenes de cultivo. 
- Cada vez que un técnico entra en el laboratorio, debe ponerse una bata de laboratorio y lavarse las manos con agua y jabón. Al salir, debe lavarse las manos de nuevo y dejar la bata colgada en un ropero en el laboratorio.

- Se prohíbe fumar o comer en el laboratorio y sentarse sobre las mesas o bancos de trabajo.

- Para asegurar la máxima seguridad, todos los procedimientos para preparar un frotis deben estar completamente estandarizados y el material siempre debe arreglarse sobre la mesa de la misma manera.

- Es preciso tener sumo cuidado al abrir los envases de esputo y preparar los frotis para evitar la formación de aerosoles.

- Los sujetadores de portaobjetos, el secador y las superficies de trabajo deben ser esterilizados bajo llama o empapados con una solución germicida, por ejemplo, fenol al 5\% o una mezcla jabonosa derivada del fenol.

- Es necesario descontaminar todos los desechos infecciosos antes de botarlos.

Los factores asociados con la transmisión nosocomial de la TB en los países industrializados ya son bien conocidos y se ha comprobado el valor de las medidas especiales implantadas para controlar o prevenir los brotes de enfermedad en instituciones de salud y laboratorios. Sin embargo, la escasez de recursos limita la importancia que pueda darse a esas medidas en países en desarrollo. En ellos se necesita recoger mucha información $\mathrm{y}$ hay una necesidad urgente de cuantificar el riesgo de TB que corre el personal de hospitales, clínicas, departamentos de rayos $\mathrm{X}$ y laboratorios y determinar los factores que han facilitado la diseminación de la TB.

Se precisa también llevar a cabo investigaciones operacionales para probar y evaluar medidas de control económicas, sostenibles y efectivas en función del costo. En los ministerios de salud y los programas nacionales sobre tuberculosis se necesita considerar medidas de contención, tales como el tamizaje voluntario del VIH en trabajadores de salud (para transferir a los que tienen la infección por VIH a áreas de bajo riesgo) e instituir terapia preventiva con isoniazida para el personal en alto riesgo de TB con el fin de determinar la eficacia protectora de estas medidas. Además, se necesitan recursos adicionales que permitan poner en práctica todas las medidas preventivas actualmente recomendadas. Los trabajadores de salud de todos los niveles son un recurso vital escaso en muchos países y urge asegurar que puedan continuar sus servicios protegiéndolos contra el riesgo ocupacional de TB.

\section{SYNOPSIS}

\section{Protection of health care workers against tuberculosis}

The rise in tuberculosis (TB) throughout the world, fueled by the pandemic of infection with the human immunedeficiency virus and with multidrug resistant strains of the bacillus, poses a great occupational hazard to health workers. In developing countries, nosocomial transmission of tuberculosis calls for preventive measures that are costeffective. This article describes time-tested interventions that have helped reduce transmission, including some administrative, diagnostic, therapeutic, and protective measures for the benefit of health workers. Attention is drawn to factors that are associated with the transmission of TB to health personnel, to efficient ways of handling patients in whom TB is suspected, and to special measures for the protection of laboratoy staff. 